\title{
DETAILED GEOMORPHOLOGICAL MAPPING OF THE SEA BOTTOM ON THE BASIS OF THE SOUTHERN BALTIC
}

DOI: http://dx.doi.org/10.18509/GBP.2015.07

UDC: 528.94:551.462(261.24)(438)

\author{
Dr. Kazimierz Szefler ${ }^{1}$ \\ Prof. Stanisław Rudowski ${ }^{1}$ \\ Dr. Radosław Wróblewski ${ }^{1,2}$ \\ Msc. Patryk Sitkiewicz ${ }^{2}$ \\ ${ }^{1}$ Maritime Institute in Gdansk, Poland \\ ${ }^{2}$ University of Gdansk, Poland
}

\begin{abstract}
Selected examples of the detailed sea bottom geomorphological mapping from the Southern Baltic are presented. The offered assortment of different types of the bottom relief, which included macro, mezo and micro forms, show great possibility of using new non-invasive methods. The main method is the generation of digital elevation models based on multibeam echosounder registrations (MBS), which cover the whole surface of the surveyed seabed with accuracy higher than $10 \mathrm{~cm}$. Additionally a simultaneous registration carried out by the side scan sonar gives an image of the bottom character. It is an underwater equivalent of LiDAR and airborne scanning on land. A further significant supplement of sea bottom recognition is provided by seismoacoustic profiling and grab or core samples. High accuracy of location of all data is ensured by the RTK GPS and Navigation System. Detailed geomorphological maps are necessary in order to perform any scientific and/or economical actions in the nearshore and open sea area.
\end{abstract}

Keywords: surface relief; subaqueous mapping; multibeam images; Ustka Bay, Baltic;

\section{INTRODUCTION}

The aim of the carried out work is the presentation of the application of new survey equipment, which enables precise recognition and mapping of the sea bottom relief. It is especially important for nearshore areas in terms of shore protection against abrasion and for management of the nearshore zone.

The nearshore area of the seabed of the Ustka Bay (fig. 1.) was chosen for the presentation of obtained results. In the mentioned area detailed surveys were carried out for many years [1] in relation to intense anthropopressure in the region (harbor, power and telecommunication cables, hard numerous methods of protecting the shore against abrasion).

The sea bottom of the Ustka Bay is mostly sandy with partially dune and cliffy shores of moraine uplands. The sea bottom of the bay is relatively shallow (up to $20 \mathrm{~m}$ of depth) with a distinct strip of nearshore bars [2], [3]. 


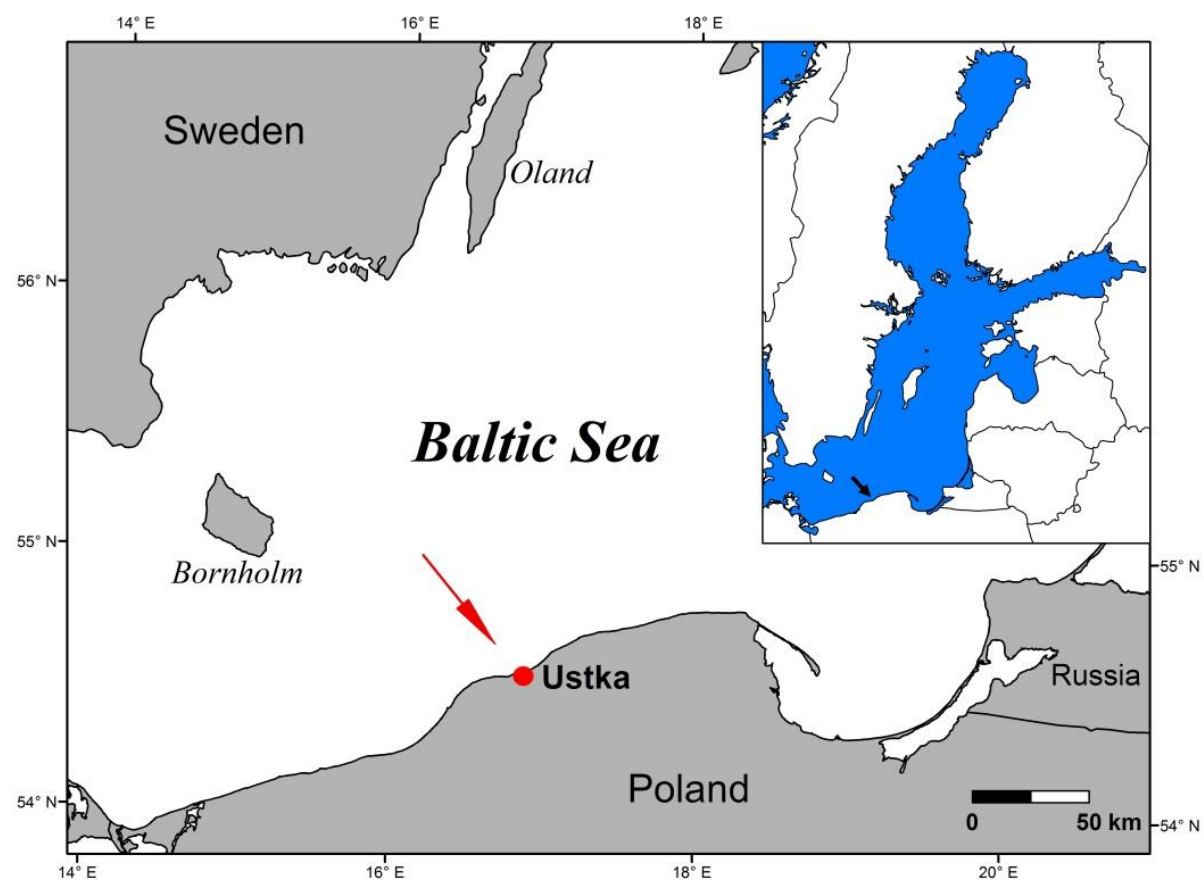

Fig. 1. Location of the study area.

\section{METHODS}

The surveys of the seabed were performed from aboard the r/v IMOR in 2014. A highresoultion multibeam echosounder (MBES, type Reason SeaBat 7101) and Side Scan Sonar were used in the surveys. Detailed positioning was performed with the DGPS RTK Trimble SPS 851 system together with Ixsea Hydrins inertial navigational system, which were integrated with the MBES, obtaining decimetre accuracy of point location.

A digital terrain model and then a detailed bathymetric map were generated on the basis of the MBES survey data. Surveys performed with a side scan sonar provided the basis for elaborating the character of the sea bottom surface and then along with the bathymetric surveys they were used for the preparation of a geomorphological sketch. Information obtained from the collection of grab samples and sea bottom sediment cores as well as results of seismic profiling (Sediment Echo Sounder type SES-96/SES-2000, 4 kHz) were used for the elaboration of survey data and their interpretation.

\section{RESULTS}

The detailed bathymetric map (fig. 2) presents the diverse image of the sea bottom relief with denivelations from a couple to a dozen meters. The geomorphological sketch (fig. 3), which included main sea bottom forms was educed and presented in combination with the sonar image. The strip of bars has a width up to $500 \mathrm{~m}$. Usually a system of two bars occurs, which are generally parallel to the shore. The layout of these forms undergoes frequent changes, including both their height and outline. The long shore slope with an inclination up to 4 degrees has a thin sandy cover (up to $0.5 \mathrm{~m}$ thickness) and forms an area of intense rubble redeposition from the shore to the sea. During storms the shore, bars and the slope are heavily eroded (fig. 4). In places of extremely severe erosion substrate sediments (e.g. fluvial sand, peat, clay, till) are uncovered and/or nearly uncovered (relatively permanently) in hollows (fig. 5). 


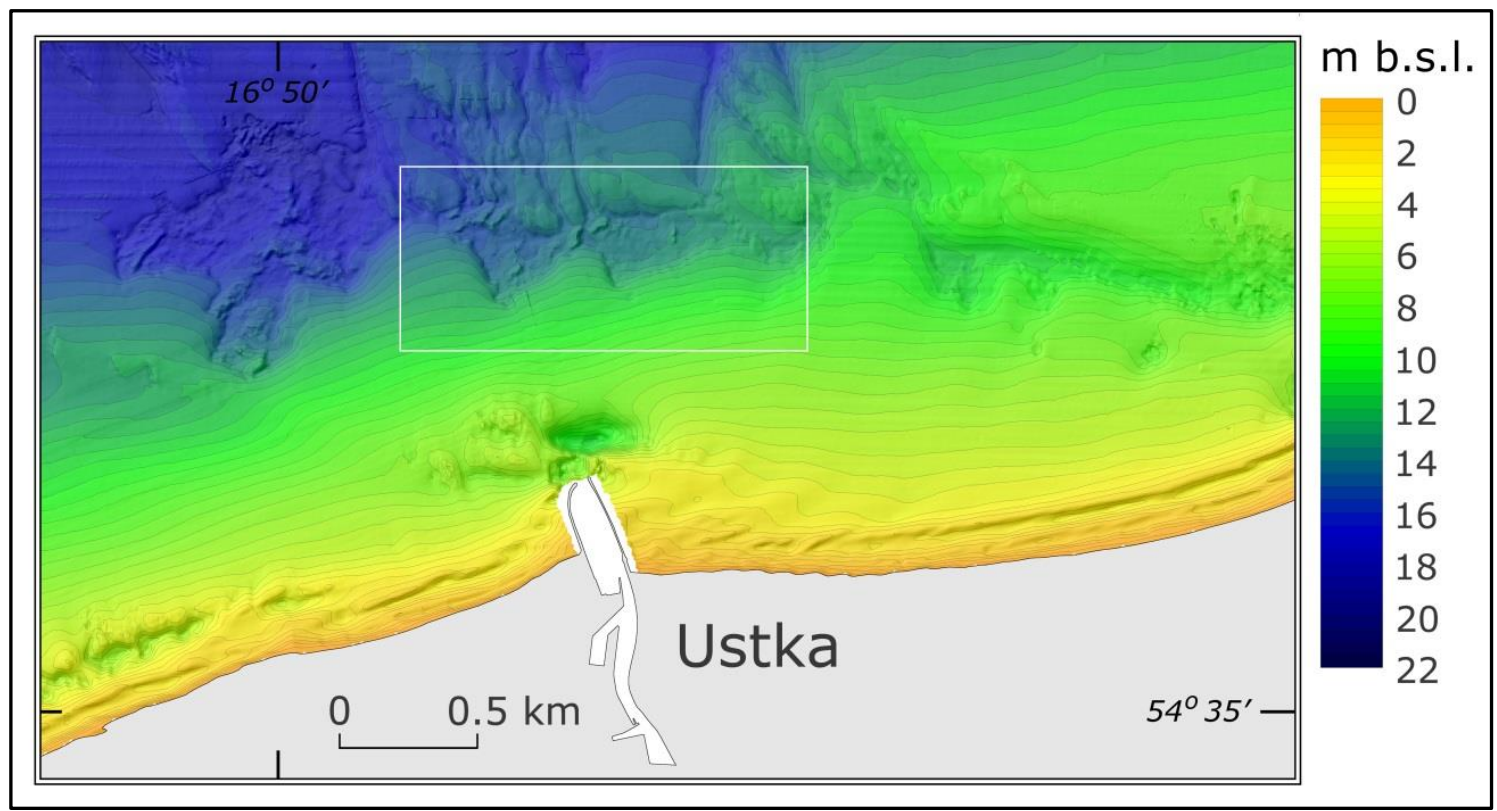

Fig. 2. Relief of the Ustka Bay bottom (based on Digital Bottom Model from MBES). White frame indicates Fig. 4 location.

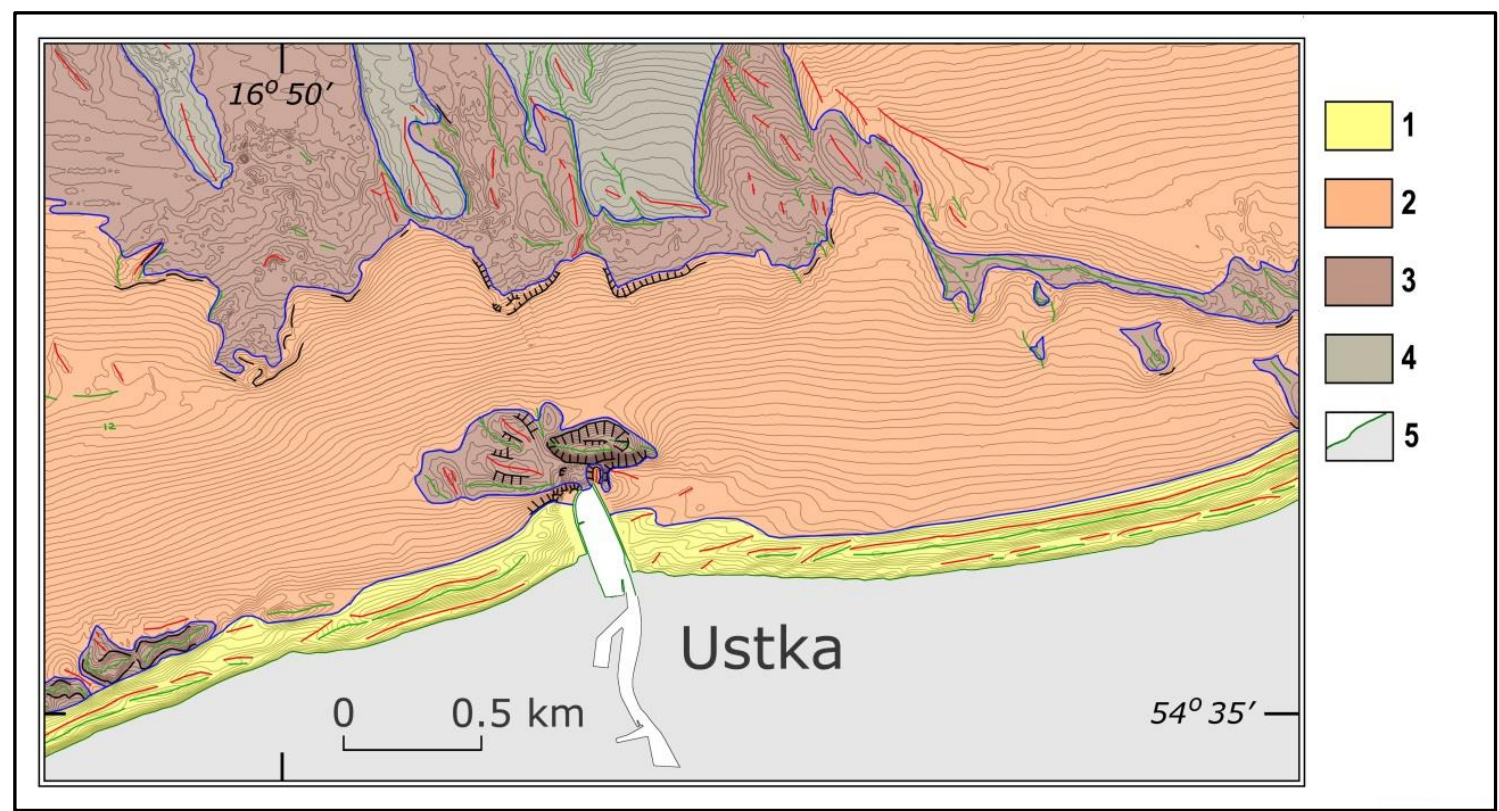

Fig. 3. Geomorphological sketch: 1- nearshore bars zone; 2- shore slope; 3- modern erosion incision; 4- modern accumulation lobes; 5- land.

In the western part of the seabed, which is located beyond the shore slope, there are numerous modern and relict forms associated with the development of the shoreline from the end of the Littorine transgression until today (these are mainly forms such as vast deltas and sand barriers). In most of the area the sandy cover is so thin that it does not mask the lithology and relief of the substratum, therefore it is marked on the sketch as an erosive area. Big, fresh sandbanks marked as fresh alluvium are an exception.

In the eastern part of the surveyed sea bottom there are fresh alluvia related to numerous sand waves, including very big ones, up to $600-700 \mathrm{~m}$ spacing between the ridges, with a small relative height up to $2 \mathrm{~m}$. 


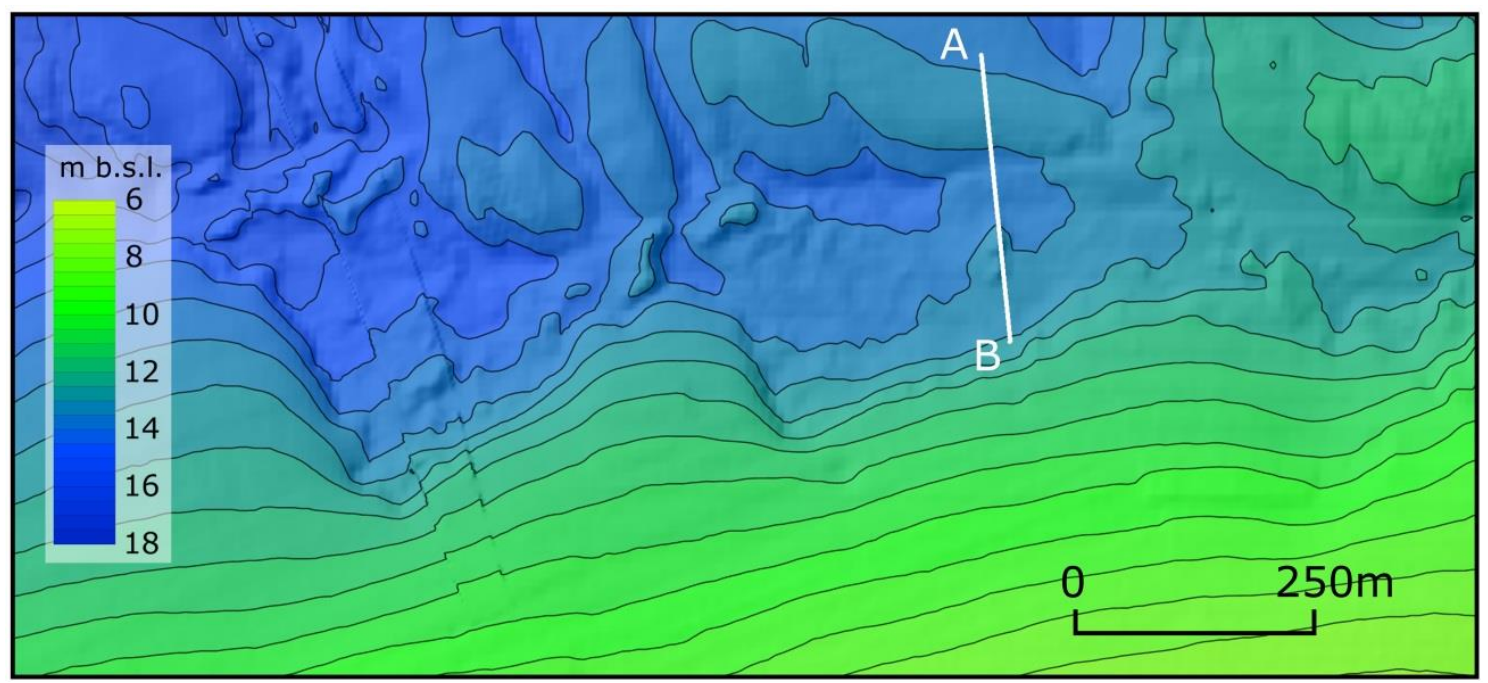

Fig. 4. Example of the erosion incisions, location A-B seismic profile.

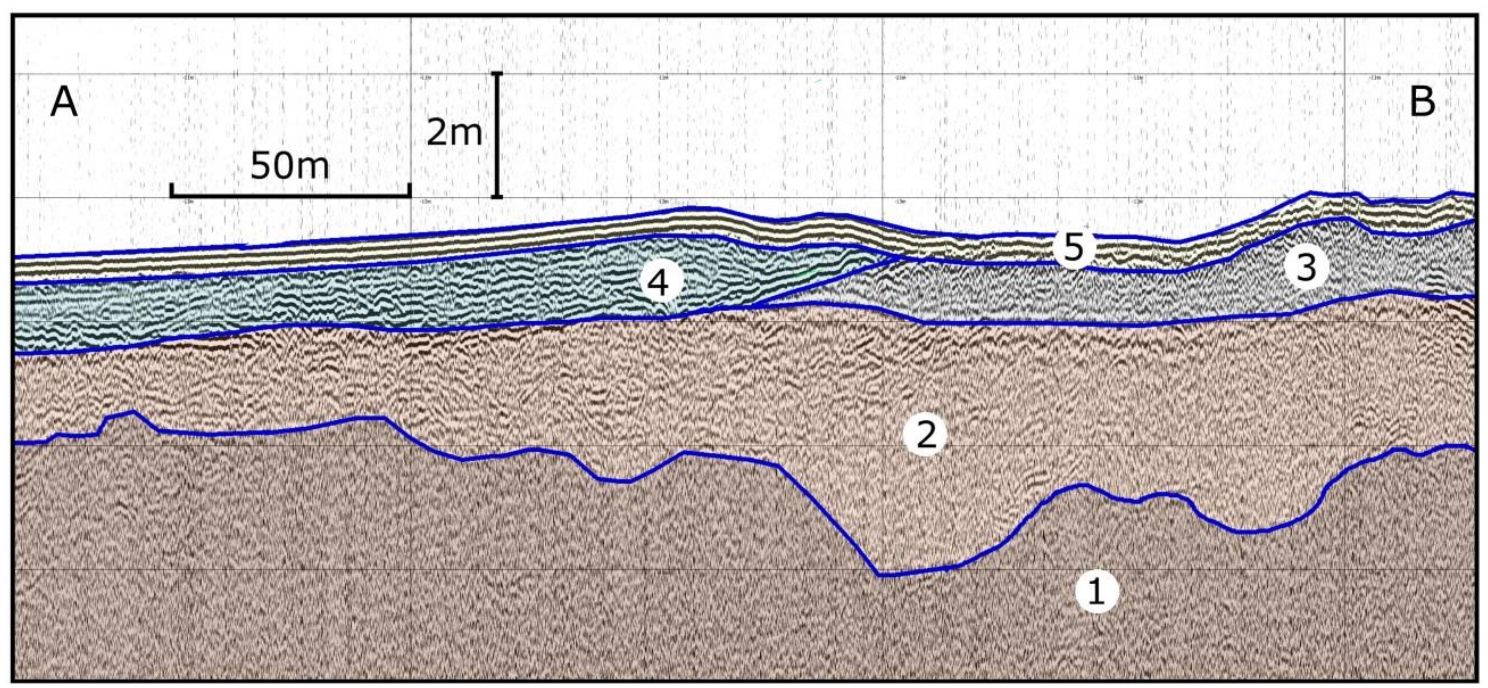

Fig. 5. Seismic profile based on Sediment Echo Sounder (SES-96/SES-2000).

Seismic units are geological interpreted as: 1- glacial till; 2- fluvioglacial sand and gravel;

3- fluvial sand and mud; 4- transgression marine sand; 5- modern marine sand (dynamic layer).

\section{CONCLUSION}

The used methods for the first time have revealed a diverse relief of the area's seabed, which was previously treated as rather flat (except for the strip of bars). The identified zones of erosion, redeposition and accumulation indicate an intense washing out of shore rubble into the sea. This clearly explains the negative balance of sediments in the nearshore area and intense abrasion of the shores despite insistent, but ineffective attempts to protect them.

The performed elaboration with the use of the discussed methods provide the perfect basis for various monitoring studies, allowing accurate measurements, rather than estimating the changes of the seabed.

Moreover the obtained results indicate the necessity to cover the seabed of the southern Baltic nearshore with monitoring surveys up to the $20 \mathrm{~m}$ isobath that is about $3 \mathrm{~km}$ and more from the shore. It is here that the change of the storm wave motion can start, when 
moving over the shallowing seabed. This determines further, increasing changes of wave motion.

\section{REFERENCES}

[1] Florek W., Rudowski S. \& Szefler K. Palaeo-Valleys in the Region of the Stupia River Mouth, Questiones Geographicae, Poznań, Poland, pp 27-36, 2010.

[2] Mojski J.E. (ed.). Geological Atlas of the Southern Baltic, Polish Geological Institute, Sopot-Warszawa, 34 plates, 1995.

[3] Mojski J.E. (ed.). Geological Atlas of the Southern Baltic, Explanations, Polish Geological Institute, Sopot-Warszawa, 63 pp, 1995. 
International Scientific Conference GEOBALCANICA 2015 